\title{
Efek Peningkatan Jumlah Paralel Korpus Pada Penerjemahan Kalimat Bahasa Indonesia ke Bahasa Lampung Dialek Api
}

\author{
${ }^{1}$ Permata, ${ }^{2}$ Zaenal Abidin \& ${ }^{3}$ Farida Ariyani \\ ${ }^{1}$ Program Studi Informatika, ${ }^{2}$ Program Studi Sistem Informasi, Univeristas Teknokrat Indonesia, Jalan Z.A Pagar Alam \\ No.9-1, Bandarlampung, Indonesia \\ ${ }^{3}$ Program Studi Magister Pendidikan Bahasa dan Kebudayaan Lampung, Univeristas Lampung, Jalan Prof. Soemantri \\ Brojonegoro No. 1, Bandarlampung, Indonesia \\ e-mail : ${ }^{1}$ permata@teknokrat.ac.id, ${ }^{2}$ zabin@ @eknokrat.ac.id, ${ }^{3}$ farida.ariyani@fkip.unila.ac.id
}

\begin{abstract}
Experimental observations of the effect of the number of parallel corpus on Indonesian translation into the Lampung dialect api were carried out using the statistical machine translation (SMT) method. SMT utilizes a parallel Indonesian corpus and its translation in the Lampung dialect api as a material for training data. The research strategy was carried out in three ways, namely first strategy with a corpus parallel number of 1000 sentences, the second strategy with a corpus parallel number of 2000 and the third strategy with a corpus parallel number of 3000 sentences. The research starts from the preprocessing phase followed by the training phase, namely the parallel corpus processing phase to obtain a language model and translation model. Then the testing phase, and ends with the evaluation phase. SMT testing uses 25 single sentences without out-of-vocabulary (OOV), 25 single sentences with OOV, 25 compound sentences without OOV and 25 compound sentences with OOV. The test results of translating Indonesian sentences into Lampung dialectic api are shown through the accuracy value of Bilingual Evaluation Undestudy (BLEU) obtained in testing 25 single sentences without out-of-vocabulary (OOV) in the first strategy, the second and the third are $21.49 \%, 59.58 \%$ and $73.21 \%$. In testing 25 single sentences with out-of-vocabulary (OOV) obtained in the first strategy, the second and the third are $23.22 \%$, $44.33 \%$ and $68.72 \%$. In testing 25 compound sentences without out-of-vocabulary (OOV) obtained in the first strategy, the second and the third are $18.22 \%, 39.4 \%$ and $69.18 \%$. In testing 25 compound sentences with out-of-vocabulary (OOV) obtained in the first strategy, the second and the third are $25.94 \%, 28.22 \%$ and $71.94 \%$.
\end{abstract}

Keywords: Paralel Corpus; Monocorpus; Statistical Machine Translation; Bilingual Evaluation Undestudy; out-of-vocabulary.

\section{PENDAHULUAN}

Beberapa upaya eksperimen otomatisasi penelitian penerjemahan bahasa Indonesia ke berbagai bahasa daerah mulai telah dilakukan dalam kurun waktu 10 tahun terakhir ini termasuk bahasa Lampung[1][2]. Secara umum di provinsi Lampung terdapat bahasa Lampung yang memiliki dua dialek utama yaitu dialek api dan dialek nyo. Pada penelitian ini difokuskan pada upaya eksperimen otomatisasi penerjemahan bahasa Indonesia ke bahasa Lampung dialek api, menggunakan tool Moses. Tool ini dapat diakses di laman (http://www.statmt.org/moses/). Penelitian ini bertujuan untuk investigasi awal dalam pengembangan mesin penerjemah pada bahasa Indonesia dan bahasa Lampung dialek api berdasarkan pendekatan Statistical Machine Translation (SMT). Penelitian penerjemahan bahasa Lampung dialek api ke bahasa Indonesia telah dilakukan[1][2][3]. Sedangkan penelitian bahasa Lampung dari aspek riset speech pertama kali dilakukan oleh Saniati,dkk[4]. Bahasa Indonesia sebagai bahasa pemersatu bangsa dan bahasa Lampung sebagai sebuah kekayaan budaya bagi masyarakat di provinsi Lampung.

Penelitian mesin penerjemah di Indonesia telah dilakukan oleh para peneliti diantaranya penerjemahan bahasa Jawa dan Bahasa Indonesia dengan SMT berbasis frasa[5], penerjemahan bahasa Sunda ke Bahasa Indonesia dengan SMT berbasis frasa dan memanfaatkan part of speech (PoS) Tag[6], bahasa Lampung juga memiliki aspek dari sisi morpologisnya[7], penerjemahan dokumen bahasa Inggris ke dokumen bahasa Indonesia dengan SMT dan word reordering dan phrase reordering [8], investigasi peran model bahasa pada penelitian SMT bahasa Indonesia-Dayak Kanayatn[9], pengaruh kuantitas korpus pada penelitian SMT bahasa Bugis 
Wajo ke bahasa Indonesia[10], penelitian penerjemahan kalimat bahasa Lampung dialek api telah menjadi objek penelitian penerjemahan secara otomatis dengan menggunakan pendekatan Neural Machine Translation (NMT) tanpa attention[1] dan NMT dengan attention[2], berbagai model penerjemahan bahasa Indonesia ke bahasa Jepang juga telah dilakukan[11], pengukuran hasil penerjemahan yang dihasilkan oleh mesin penerjemah menggunakan perhitungan skor Bilingual Evalution Understudy (BLEU)[12], pengamatan aspek morfologi bahasa Lampung telah dilakukan oleh para peneliti bahasa Lampung[13], sedangkan teori SMT diambil dari buku utama[14][15].

Penerjemahan bahasa Indonesia ke bahasa Lampung dialek api dapat dilakukan dengan menggunakan kamus bahasa Lampung yang digunakan di sekolah-sekolah. Penerjemahan, menggunakan kamus sebagai rujukan utama dalam menerjemahkan, bahasa Lampung ke bahasa Indonesia sedang diselidiki di tahun 2020 ini oleh peneliti dalam waktu yang bersamaan. Penelitian dengan metode SMT ini bertujuan untuk melakukan pengamatan terhadap hasil penerjemahan bahasa Indonesia ke bahasa Lampung dialek api dengan tiga strategi eksperimen pada bagian korpus paralel yang digunakan. Penelitian ini tidak menggunakan bahasa Lampung dialek nyo dan tidak menggunakan naskah bernuasa sastra Lampung dialek api atau nyo. Penelitian ini tidak menyertakan aspek morpologi pada bahasa yang digunakan sebagai salah satu batasan masalahnya.

\section{METODOLOGI PENELITIAN}

Eksperimen penerjemahan bahasa Indonesia ke bahasa Lampung dialek api dilakukan dengan menggunakan tool Moses Decoder. Informasi tentang SMT dengan Moses Decoder dapat diakses melalui tautan (http://www.statmt.org/moses/). Saat ini dalam menerjemahkan bahasa Indonesia ke bahasa Lampung dialek api dilakukan secara manual yaitu dengan menggunakan kamus bahasa Lampung dengan cara pencarian kata per kata yang berkesesuaian. Hasil wawancara dengan guru bahasa Lampung menunjukan bahasa Lampung memiliki kemiripan stuktur tata bahasa dengan bahasa Indonesia. Sebuah kamus bahasa Lampung - Indonesia yang diterbitkan oleh penerbit gunung pesagi Bandar Lampung berisi 4071 kata dialek Api, sedangkan kamus bahasa Indonesia edisi ke-5 yang diterbitkan oleh penerbit gramedia pustaka utama memiliki 118000 kata. Beberapa contoh kalimat dalam bahasa Indonesia dan terjemahannya dalam bahasa Lampung api dapat dilihat pada tabel 1 di bawah ini.

Tabel 21. Bahasa Indonesia dan terjemahannya dalam bahasa Lampung

\begin{tabular}{|c|c|}
\hline Bahasa Indonesia & Bahasa Lampung \\
\hline Ani tolong ambilkan air itu & Ani tulung akukko wai sina \\
\hline Ibuku sedang mencuci baju di sungai & Makku lagi mepoh kawai di wai \\
\hline Kita pergi ke pasar & Gham lapah mit pasagh \\
\hline Mari kita sholat di masjid & Lapah gham sholat di masjid \\
\hline $\begin{array}{l}\text { Ketua kelas yang mengatur barisan di } \\
\text { kelasnya }\end{array}$ & Ketua kelas sai ngator barisan di kelasni \\
\hline $\begin{array}{l}\text { Dia tetap di kelas satu karena tidak naik kelas } \\
\text { tiga kali }\end{array}$ & Ya tetap di kelas sai ulah mak cakak kelas telu kali \\
\hline
\end{tabular}

Pada tabel 1 di atas terdapat hal yang menarik yaitu pada kalimat pertama terdapat air yang dalam bahasa Lampung dialek api yaitu wai sedangkan pada kalimat kedua kata sungai yang dalam bahasa Lampung dialek api yaitu wai. Dua kata yaitu air dan sungai memiliki padanan kata yang sama yaitu wai. Beberapa kata yang memiliki makna berbeda tergantung konteks kalimat atau posisi pada kalimat, seperti kata lapah, sai. Pengguna kamus bahasa Indonesia - Lampung harus menerjemahkan satu per satu dan memilih makna kata yang tepat secara manual agar kalimat tersebut dapat dipahami dengan baik. Penerjemahan kalimat bahasa Indonesia ke bahasa Lampung dialek api adalah sangat penting dengan memperhatikan konteks kalimat yang digunakan agar dapat menghasilkan terjemahan yang sesuai. Pada bahasa Lampung juga terdapat beberapa kata yang 
memiliki satu makna yaitu lapah, mit, tandak, lijing yang semuanya bermakna pergi. Beberapa partikel seperti kudo, do, pai, tah semuanya memiliki satu makna yaitu lah, sebuah partikel dalam bahasa Indonesia.

Dalam eksperimen SMT bahasa Indonesia ke bahasa Lampung dialek api dibutuhkan korpus paralel antara bahasa Indonesia ke bahasa Lampung dialek api dan mono korpus bahasa Lampung dialek api sebagai bahan membuat language model. Pembuatan korpus paralel yang dilakukan secara manual. Korpus paralel akan dilakukan prapemrosesan kalimat secara secara manual baik pada bahasa Lampung dialek api maupun bahasa Indonesia yaitu dengan cara : (1) kalimat dibuat menggunakan semua huruf kecil, (2) antar kalimat dipisahkan oleh spasi termasuk tanda koma, tanda tanya, tanda seru dan titik.

Kalimat-kalimat, bahasa Indonesia dan terjemahannya dalam bahasa Lampung dialek api, yang digunakan dalam penelitian ini dibuat secara mandiri dengan cara mengetikkan ulang karena faktor ketiadaan bahan yang dapat diambil secara daring dari laman. Jumlah korpus paralel yang digunakan adalah 3000 kalimat adalah berasal dari buku sekolah dasar (SD) dan lembar kerja siswa (LKS) tingkat SD yang digunakan di provinsi Lampung, buku percakapan sehari-hari bahasa Lampung serta buku afiksasi verba bahasa Lampung. Untuk keperluan penelitian 3000 kalimat korpus paralel disediakan dalam tautan https://drive.google.com/drive/folders/1eIOQcgZCXSYtaoVoqSbp0w9JcFgWGBjM?usp=sharing

\subsection{Tahapan Ekperimen Penerjemahan Bahasa Indonesia - Lampung Dialek Api}

Pada penelitian ini bahan yang digunakan satu buah korpus paralel yaitu 3000 kalimat bahasa Indonesia, 3000 kalimat bahasa Lampung dialek api dan satu buah mono korpus 4000 kalimat bahasa Lampung dialek api. Korpus paralel bahasa Indonesia - bahasa Lampung dialek api digunakan untuk membuat atau membangun language model sedangkan mono korpus bahasa Lampung dialek api digunakan untuk membuat atau membangun model translasi.

Tahapan eksperimen dilakukan dengan 3 strategi, yaitu :

1. strategi pertama, eksperimen menggunakan satu buah korpus paralel yaitu 1000 kalimat bahasa Indonesia, 1000 kalimat bahasa Lampung dialek api dan satu buah mono korpus 4000 kalimat bahasa Lampung dialek api,

2. strategi kedua, eksperimen menggunakan satu buah korpus paralel yaitu 2000 kalimat bahasa Indonesia, 2000 kalimat bahasa Lampung dialek api dan satu buah mono korpus 4000 kalimat bahasa Lampung dialek api,

3. strategi ketiga, eksperimen menggunakan satu buah korpus paralel yaitu 3000 kalimat bahasa Indonesia, 3000 kalimat bahasa Lampung dialek api dan satu buah mono korpus 4000 kalimat bahasa Lampung dialek api.

Strategi pertama digunakan sebagai baseline untuk pengamatan hasil penerjemahan bahasa Indonesia ke bahasa Lampung dialek api, kemudian akan dilihat hasilnya pada strategi kedua dan ketiga. Adapun pengujian penelitian ini dilakukan dengan menggunakan 100 kalimat uji terdiri dari 25 kalimat tunggal tanpa out of vocobulary (OOV) disingkat menjadi TTOOV, 25 kalimat tunggal dengan OOV disingkat menjadi TDOOV, 25 kalimat majemuk tanpa OOV disingkat menjadi MTOOV dan 25 kalimat majemuk dengan OOV disingkat menjadi MDOOV.

\subsection{Statistical Machine Translation}

Dalam melakukan uji coba penerjemahan secara statistik bahasa Indonesia ke bahasa Lampung dialek api, peneliti menggunakan arsitektur SMT yang digunakan dalam penelitian menggunakan penelitian[5]. Ujicoba ini di mulai dari fase prapemrosesan yang merupakan tahapan awal untuk mempersiapkan korpus parallel. Kemudian dilanjutkan dengan fase training, yakni fase pengolahan korpus parallel untuk memperoleh language model dan translation model. Selanjutnya fase testing, dan diakhiri dengan fase evaluasi. Untuk alatalat (tools) yang digunakan dalam ujicoba SMT pada bahasa Indonesia-Lampung dialek api adalah :

1. Linux ubuntu 16.04 LTS, sistem operasi yang digunakan dalam menjalankan Moses.

2. Moses, perangkat lunak untuk proses preprosesing dan decoding. 
3. KenLM, perangkat lunak telah terpasang di Moses, untuk Language Model.

4. Giza++, perangkat lunak untuk Translation Model.

5. BLEU, perangkat lunak untuk proses evaluasi.

\subsection{Implementasi SMT Pada Moses Decoder}

Fase prapemrosesan SMT pada Moses Decoder terdiri dari beberapa bagian, yakni penjajaran kalimat, tokenisasi, cleaning, lowercase filtering, dan truecase. Penjajaran kalimat adalah proses menjajarkan korpus paralel bahasa Indonesia ke bahasa lampung dialek api sebagai terjemahannya. Tokenisasi diperlukan untuk memberi jarak antar kata termasuk juga memberi jarak antara kata dengan tanda baca yang ada, sedangkan lowercase merupakan proses untuk menyeragamkan besar-kecilnya huruf. Detail sintaks yang digunakan dalam penelitian ini terdapat di tautan (https://drive.google.com/drive/folders/1eIOQcgZCXSYtaoVoqSbp0w9JcFgWGBjM?usp=sharing)

\section{HASIL DAN PEMBAHASAN}

Hasil eksperimen pada SMT bahasa Indonesia ke bahasa Lampung dialek api disajikan secara detail pada tautan (https://drive.google.com/drive/folders/1eIOQcgZCXSYtaoVoqSbp0w9JcFgWGBjM?usp=sharing). Eksperimen menggunakan tiga strategi pada bahan penelitian memberikan hasil yang menarik untuk diamati secara numerik dan analisis pada masing-masing bagian-bagian pada 100 kalimat uji terdiri dari 25 kalimat tunggal tanpa out of vocobulary (OOV) disingkat menjadi TTOOV, 25 kalimat tunggal dengan OOV disingkat menjadi TDOOV, 25 kalimat majemuk tanpa OOV disingkat menjadi MTOOV dan 25 kalimat majemuk dengan OOV disingkat menjadi MDOOV. Akurasi hasil penerjemahan dari bahasa Indonesia ke bahasa Lampung dialek api disajikan di tabel 2 dalam persen (\%).

Tabel 2. Hasil skor BLEU eksperimen SMT bahasa Indonesia ke bahasa Lampung dialek api

\begin{tabular}{lccc}
\hline Kalimat Uji & $\begin{array}{c}\text { Strategi } \\
\mathbf{1}\end{array}$ & $\begin{array}{c}\text { Strategi } \\
\mathbf{2}\end{array}$ & $\begin{array}{c}\text { Strategi } \\
\mathbf{3}\end{array}$ \\
\hline TTOOV & 21.49 & 59.58 & 73.21 \\
TDOOV & 23.22 & 44.33 & 68.72 \\
MTOOV & 18.22 & 39.4 & 69.18 \\
MDOOV & 25.94 & 28.22 & 71.94 \\
\hline
\end{tabular}

Pada strategi pertama, hasil yang didapat adalah rendahnya akurasi penerjemahan bahasa Indonesia ke bahasa Lampung dialek api baik pada bagian TTOOV, TDOOV, MTOOV dan MDOOV. Nilai akurasi tertinggi hanya dicapai pada MDOOV, eksperimen penerjemahan kalimat uji berupa kalimat majemuk dengan ada OOV didalamnya, sebesar $25.94 \%$. Hal menarik yang muncul pada strategi pertama ini adalah hasil akurasi pada uji coba kalimat tunggal dan kalimat majemuk yaitu terjadi peningkatan akurasi ketika dengan sengaja diberikan kata yang tidak ada di dalam korpus paralel atau disebut OOV. Hal ini disebabkan minimnya informasi n-grams yang diperoleh dari hasil pembangkitan model bahasa menggunakan korpus paralel sejumlah 1000 kalimat Indonesia, 1000 kalimat bahasa Lampung dialek api.

Pada strategi kedua, eksperimen menggunakan satu buah korpus paralel yaitu 2000 kalimat bahasa Indonesia, 2000 kalimat bahasa Lampung dialek api dan satu buah mono korpus 4000 kalimat bahasa Lampung dialek api. Hasilnya menunjukan bahwa penambahan korpus paralel 1000 kalimat secara signifikan meningkatkan akurasi pada TTOOV sebesar $38.09 \%$ dari sebelumnya strategi pertama, pada TDOOV sebesar $21.11 \%$ dari sebelumnya strategi pertama, pada MTOOV sebesar $21.18 \%$ dari sebelumnya strategi pertama dan pada MDOOV sebesar $2.28 \%$ dari sebelumnya strategi pertama. Peningkatan yang paling kecil terjadi di bagian MDOOV. 
Tabel 3. Hasil peningkatan akurasi

\begin{tabular}{lcc}
\hline $\begin{array}{l}\text { Peningkatan } \\
\text { Akurasi }\end{array}$ & $\begin{array}{c}\text { Dari Strategi 1 } \\
\text { menjadi Strategi 2 }\end{array}$ & $\begin{array}{c}\text { Dari Strategi 2 } \\
\text { menjadi Strategi 3 }\end{array}$ \\
\hline TTOOV & 38.09 & 13.63 \\
TDOOV & 21.11 & 24.39 \\
MTOOV & 21.18 & 29.78 \\
MDOOV & 2.28 & 43.72 \\
\hline
\end{tabular}

Pada strategi ketiga, eksperimen menggunakan satu buah korpus paralel yaitu 3000 kalimat bahasa Indonesia, 3000 kalimat bahasa Lampung dialek api dan satu buah mono korpus 4000 kalimat bahasa Lampung dialek api. Hasilnya menunjukan bahwa penambahan korpus paralel 2000 kalimat secara signifikan meningkatkan akurasi pada TTOOV sebesar $51.72 \%$ dari sebelumnya strategi pertama, pada TDOOV sebesar $45.5 \%$ dari sebelumnya strategi pertama, pada MTOOV sebesar $50.96 \%$ dari sebelumnya strategi pertama dan pada MDOOV sebesar $46 \%$ dari sebelumnya strategi pertama. Peningkatan jumlah korpus paralel secara signifikan meningkatkan akurasi hasil penerjemahan dari bahasa Indonesia ke bahasa Lampung dialek api.

\subsection{Analisis Hasil TTOOV}

Hasil eksperimen pada SMT bahasa Indonesia ke bahasa Lampung dialek api yang disajikan pada tabel 2 menunjukan informasi peningkatan akurasi dari strategi 1, strategi 2 menuju strategi 3. Detail hasil ada di tautan(https://drive.google.com/drive/folders/1eIOQcgZCXSYtaoVoqSbp0w9JcFgWGBjM?usp=sharing).

Hasil eksperimen, menggunakan 25 kalimat tunggal tanpa out of vocobulary (OOV) disingkat menjadi TTOOV, menunjukan peningkatan akurasi sebesar 38.09\% dari strategi 1 menuju strategi 2 sedangkan dari strategi 2 menuju strategi 3 hanya menambah $13.63 \%$ akurasinya. Detail hasil SMT TTOOV ada di tautan di bagian wah ini.

Hasil pengamatan yang diberikan pada tautan tersebut menunjukan pada strategi pertama SMT memberikan hasil penerjemahan berupa kalimat yang berisi campuran antara kata bahasa Indonesia dan kata dalam bahasa Lampung dialek api walaupun demikian SMT mampu memberikan hasil berupa kalimat. Sebuah contoh hasil SMT diberikan pada tabel 4 di bawah ini. Pada strategi 2, SMT secara umum memberikan hasil sepenuhnya kalimat berbahasa Lampung api walaupun susunan posisinya kalimatnya masih tertukar sedangkan pada strategi 3 hasil SMT lebih baik dari strategi 2.

Tabel 4. Contoh hasil TTOOV

\begin{tabular}{|c|c|}
\hline Kalimat Uji (TTOOV) & saya tidak mencuci baju di sungai \\
\hline $\begin{array}{l}\text { Hasil terjemahan acuan oleh penutur bahasa } \\
\text { Lampung } A p i\end{array}$ & nyak mak mepoh kawai di wai \\
\hline Output strategi 1 & nyak mak mencuci baju dipa-dipa sungai \\
\hline Output strategi 2 & nyak mak mepoh kawai di wai \\
\hline Output strategi 3 & nyak mak mepoh kawai di wai \\
\hline
\end{tabular}




\subsection{Analisis Hasil TDOOV}

Hasil eksperimen pada SMT bahasa Indonesia ke bahasa Lampung dialek api yang disajikan pada tabel 2 menunjukan informasi peningkatan akurasi dari strategi 1, strategi 2 menuju strategi 3. Detail hasil ada di tautan(https://drive.google.com/drive/folders/1eIOQcgZCXSYtaoVoqSbp0w9JcFgWGBjM?usp=sharing). Pada TDOOV pada prinsipnya menggunakan kalimat yang sama seperti pada TTOOV. Perbedaan mendasarnya adalah adanya penambahan kata yang berperan sebagai out of vocobulary (OOV). Hasil eksperimen, menggunakan 25 kalimat tunggal dengan out of vocobulary (OOV) disingkat menjadi TDOOV, menunjukan adanya pengaruh pada hasil penerjemahan SMT sehingga peningkatan akurasi hanya sebesar $21.11 \%$ dari strategi 1 menuju strategi 2 akan tetapi dari strategi 2 menuju strategi 3 hasilnya lebih tinggi yaitu menambah $24.39 \%$ akurasinya.

Hasil pengamatan yang diberikan pada tautan tersebut menunjukan pada strategi pertama SMT memberikan hasil penerjemahan berupa kalimat yang berisi campuran antara kata bahasa Indonesia dan kata dalam bahasa Lampung dialek api walaupun demikian SMT mampu memberikan hasil berupa kalimat. Sebuah contoh hasil SMT diberikan pada tabel 5 di bawah ini. Pada strategi 2, SMT secara umum memberikan hasil sepenuhnya kalimat berbahasa Lampung api walaupun demikian kata OOV belum terakomodasi dengan baik bahkan hilang sedangkan pada strategi 3 hasil SMT lebih baik dari strategi 2.

Tabel 5. Contoh hasil TDOOV

\begin{tabular}{|c|c|}
\hline Kalimat Uji (TDOOV) & \multirow{5}{*}{$\begin{array}{l}\text { saya tidak mencuci baju di sungai brantas } \\
\text { nyak mak mepoh kawai di wai brantas } \\
\text { nyak mak mencuci baju dipa-dipa sungai brantas }\end{array}$} \\
\hline $\begin{array}{l}\text { Hasil terjemahan acuan oleh penutur bahasa } \\
\text { Lampung } A p i\end{array}$ & \\
\hline Output strategi 1 & \\
\hline Output strategi 2 & \\
\hline Output strategi 3 & \\
\hline
\end{tabular}

\subsection{Analisis Hasil MTOOV}

Hasil eksperimen pada SMT bahasa Indonesia ke bahasa Lampung dialek api yang disajikan pada tabel 2 menunjukan informasi peningkatan akurasi dari strategi 1, strategi 2 menuju strategi 3. Detail hasil ada di tautan(https://drive.google.com/drive/folders/1eIOQcgZCXSYtaoVoqSbp0w9JcFgWGBjM?usp=sharing).

Pada MTOOV pada prinsipnya menggunakan kalimat majemuk guna melihat kemampuan SMT dalam menerjemahkan kalimat bahasa Indonesia yang tidak sederhana tapi dengan tetap mempertahankan tanpa OOV. Hasil eksperimen, menggunakan 25 kalimat majemuk dengan out of vocobulary (OOV) disingkat menjadi MTOOV, menunjukan adanya pengaruh pada hasil penerjemahan SMT sehingga peningkatan akurasi hanya sebesar $21.18 \%$ dari strategi 1 menuju strategi 2 akan tetapi dari strategi 2 menuju strategi 3 hasilnya lebih tinggi yaitu menambah $29.78 \%$ akurasinya. Artinya penambahan jumlah korpus paralel berkontribusi positif.

Hasil pengamatan yang diberikan pada tautan tersebut menunjukan pada strategi pertama SMT memberikan hasil penerjemahan berupa kalimat yang berisi campuran antara kata bahasa Indonesia dan kata dalam bahasa Lampung dialek api walaupun demikian SMT mampu memberikan hasil berupa kalimat. Sebuah contoh hasil SMT diberikan pada tabel 6 di bawah ini. Pada strategi 2, SMT secara umum memberikan hasil sepenuhnya 
kalimat berbahasa Lampung api walaupun susunan kata yang dibentuk masih tertukar secara posisi dan masih ada kata yang berbahasa Indonesia sedangkan pada strategi 3 hasil SMT lebih baik dari strategi 2.

Tabel 6. Contoh hasil MTOOV

\begin{tabular}{|c|c|}
\hline Kalimat Uji (TDOOV) & $\begin{array}{l}\text { tuan-tuan yth memancing walau anak-anak nya } \\
\text { tidak ada yang menjaga di pantai }\end{array}$ \\
\hline $\begin{array}{l}\text { Hasil terjemahan acuan oleh penutur bahasa } \\
\text { Lampung } A p i\end{array}$ & $\begin{array}{l}\text { kuti ghumpok ngawil walau sanak-sanak ni mak } \\
\text { wat sai ngejaga di pantai }\end{array}$ \\
\hline Output strategi 1 & $\begin{array}{l}\text { tuan-tuan yth memancing walau anak-anak di } \\
\text { mak ngedok sai menjaga di pantai }\end{array}$ \\
\hline Output strategi 2 & $\begin{array}{l}\text { sanak-sanak kuti ghumpok memancing kipak } \\
\text { ngejaga ni mak ngedok sai di pantai }\end{array}$ \\
\hline Output strategi 3 & $\begin{array}{l}\text { kuti ghumpok ngawil walau sanak-sanak ni mak } \\
\text { ngedok sai ngejaga di pantai }\end{array}$ \\
\hline
\end{tabular}

\subsection{Analisis Hasil MDOOV}

Hasil eksperimen pada SMT bahasa Indonesia ke bahasa Lampung dialek api yang disajikan pada tabel 2 menunjukan informasi peningkatan akurasi dari strategi 1, strategi 2 menuju strategi 3. Detail hasil ada di tautan(https://drive.google.com/drive/folders/1eIOQcgZCXSYtaoVoqSbp0w9JcFgWGBjM?usp=sharing).

Pada MDOOV pada prinsipnya menggunakan kalimat majemuk guna melihat kemampuan SMT dalam menerjemahkan kalimat bahasa Indonesia yang tidak sederhana dan dengan sengaja menambahan sebuah kata OOV. Hasil eksperimen, menggunakan 25 kalimat majemuk dengan out of vocobulary (OOV) disingkat menjadi MDOOV, menunjukan hampir tidak adanya pengaruh pada penambahan jumlah paralel korpus dari hasil penerjemahan SMT yang hanya meningkat sebesar $2.28 \%$ dari strategi 1 menuju strategi 2 akan tetapi dari strategi 2 menuju strategi 3 hasilnya lebih tinggi yaitu menambah $43.72 \%$ akurasinya. Artinya penambahan jumlah korpus paralel berkontribusi positif walaupun terdeteksi adanya OOV. Penambahan OOV memberikan kontribusi positif pada language model yang dihasilkan.

Hasil pengamatan yang diberikan pada tautan tersebut menunjukan pada strategi pertama SMT memberikan hasil penerjemahan berupa kalimat yang berisi campuran antara kata bahasa Indonesia dan kata dalam bahasa Lampung dialek api walaupun demikian SMT mampu memberikan hasil berupa kalimat. Sebuah contoh hasil SMT diberikan pada tabel 7 di bawah ini. Pada strategi 2, SMT secara umum memberikan hasil sepenuhnya kalimat berbahasa Lampung api walaupun demikian kata penambahan jumlah korpus paralel tidak berkontribusi positif dan juga dipengaruhi OOV sedangkan pada strategi 3 hasil SMT lebih baik dari strategi 2. 
Tabel 7. Contoh hasil MDOOV

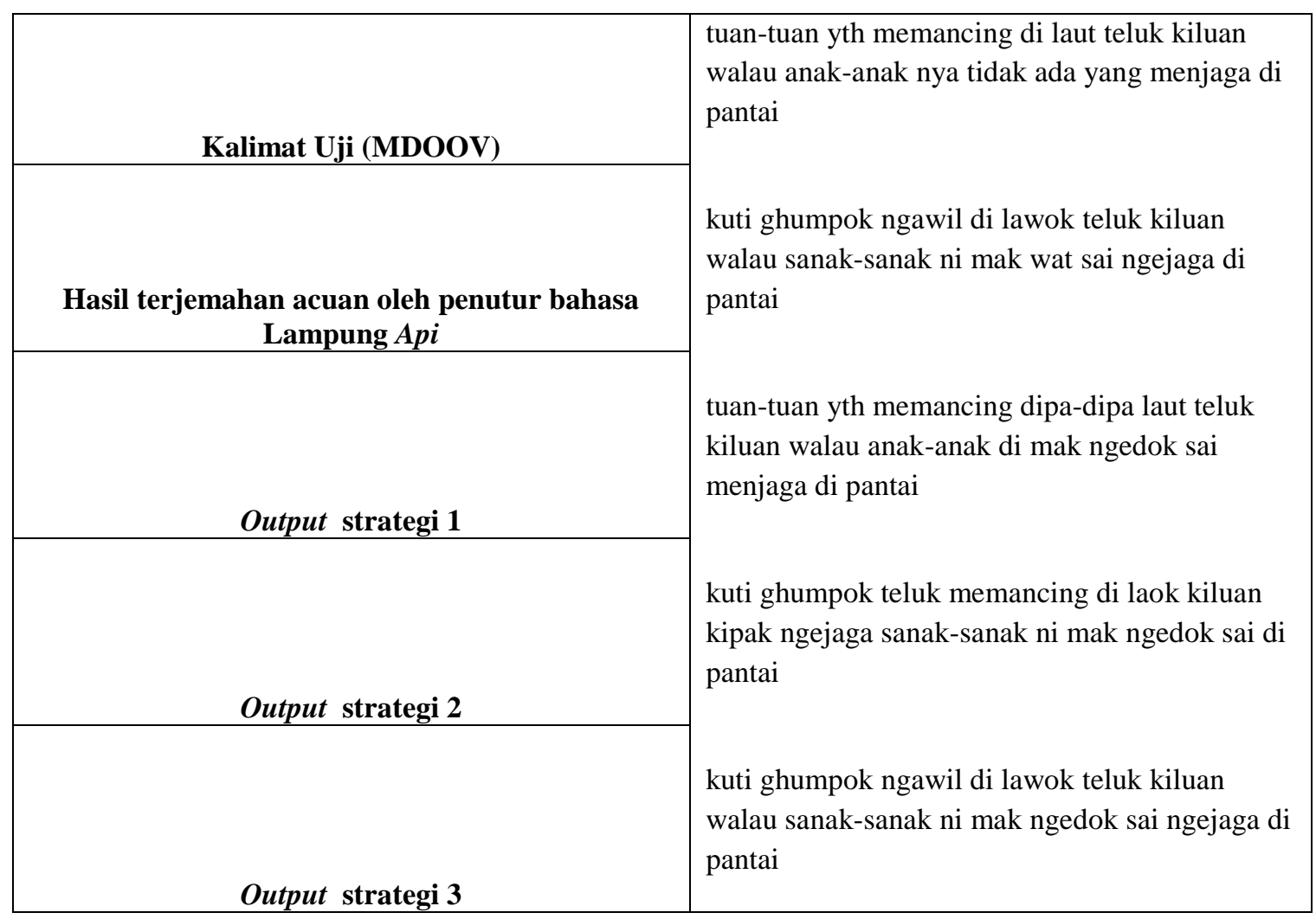

\section{KESIMPULAN}

Efek peningkatan jumlah korpus paralel pada eksperimen mesin penerjemah menggunakan metode SMT menunjukan peningkatan hasil yang positif berdasarkan perolehan pada tabel 2 dan tabel 3. Secara umum pada hasil eksperimen di strategi 1 diperolah hasil penerjemahan yang berupa kalimat walaupun berisi campuran antara bahasa Indonesia dan bahasa Lampung dialek api, pada strategi 2 diperolah hasil penerjemahan yang berupa kalimat bahasa Lampung dialek api walaupun masih tertukar posisi kata pada tempat seharusnya dan masih ditemukan sedikit kata berbahasa Indonesia, sedangkan pada strategi 3 memberikan hasil yang terbaik dibandingkan pada strategi 1 dan 2.

\section{UCAPAN TERIMA KASIH}

Penulis mengucapkan terima kasih kepada Kementrian Riset dan Teknologi / Badan Riset dan Inovasi Nasional (KEMENRISTEK/BRIN) yang telah memberi dukungan pendanaan / financial terhadap penelitian ini melalui skema Penelitian Dosen Pemula (PDP) tahun 2020 dengan nomor kontrak 023/UTI/LPPM/E.1.3/VII/2020.

\section{DAFTAR PUSTAKA}

[1] Z. Abidin, "Penerapan Neural Machine Translation untuk Eksperimen Penerjemahan secara Otomatis pada Bahasa Lampung - Indonesia," Pros. Semin. Nas. Metod. Kuantitatif 2017, no. 978, pp. 53-68, 2017.

[2] Z. Abidin, A. Sucipto, and A. Budiman, "Penerjemahan Kalimat Bahasa Lampung-Indonesia Dengan 
(C2020 Ilmu Komputer Unila Publishing Network all rights reserved

\section{Jurnal Komputasi}

Pendekatan Neural Machine Translation Berbasis Attention Translation of Sentence LampungIndonesian Languages With Neural Machine Translation Attention Based," J. Kelitbangan, vol. 06, no. 02, pp. 191-206, 2018.

[3] P. Permata and Z. Abidin, "Statistical Machine Translation Pada Bahasa Lampung Dialek Api Ke Bahasa Indonesia," Media Inform. Budidarma, vol. 4, no. 3, pp. 519-528, 2020, doi: 10.30865/mib.v4i3.2116.

[4] S. Ningsih and S. Saniati, "Eksperimen Pengenalan Ucapan Aksara Lampung Dengan CMU Sphinx 4," J. Teknoinfo, vol. 12, no. 1, p. 33, 2018, doi: 10.33365/jti.v12i1.40.

[5] R. Nugroho Aditya, T. Adji Bharata, and B. Hantono S, "Penerjemahan Bahasa Indonesia dan Bahasa Jawa Menggunakan Metode Statistik Berbasis Frasa," Semin. Nas. Teknol. Inf. dan Komun., vol. 2015, no. Sentika, 2015.

[6] A. A. Suryani, D. H. Widyantoro, A. Purwarianti, and Y. Sudaryat, "Experiment on a phrase-based statistical machine translation using PoS Tag information for Sundanese into Indonesian," 2015 Int. Conf. Inf. Technol. Syst. Innov. ICITSI 2015 - Proc., 2016, doi: 10.1109/ICITSI.2015.7437678.

[7] Megaria, "Afiks Pembentuk Adjektiva dalam Bahasa Lampung Dialek A Logat Belalau (Analisis Morfologis)," J. LOKABASA, vol. 4, no. 2, pp. 195-201, 2013.

[8] H. Tanuwijaya and H. Manurung, Maruli, "Penerjemah Dokumen Inggris-Indonesia Menggunakan Mesin Penerjemah Statistik Dengan Word Reordering dan Phrase Reordering," J. Ilmu Komput. dan Inf., vol. 2, no. 1, pp. 17-24, 2009.

[9] H. Sujaini, "Meningkatkan Peran Model Bahasa dalam Mesin Penerjemah Statistik (Studi Kasus Bahasa Indonesia-Dayak Kanayatn)," Khazanah Inform. J. Ilmu Komput. dan Inform., vol. 3, no. 2, p. 51, 2017, doi: 10.23917/khif.v3i2.4398.

[10] T. Apriani, H. Sujaini, and N. Safriadi, "Pengaruh Kuantitas Korpus Terhadap Akurasi Mesin Penerjemah Statistik Bahasa Bugis Wajo Ke Bahasa Indonesia," J. Sist. dan Teknol. Inf., vol. 1, no. 1, pp. 1-6, 2016.

[11] C. Adiputra, Krisna and Y. Arase, "Performance of Japanese-to-Indonesian Machine Translation on Different Models," Proc. 23rd Annu. Meet. Linguist. Process. Soc., no. C, pp. 7-10, 2017.

[12] K. Papineni, S. Roukos, T. Ward, and W.-J. Zhu, "BLEU: a Method for Automatic Evaluation of Machine Translation," Proc. 40th Annu. Meet. Assoc. Comput. Linguist., pp. 311-318, 2002, doi: 10.1002/andp.19223712302.

[13] F. Ariyani, "Distribusi Verba Berfrefiks (N-) Pada Bahasa Lampung dalam Kitab Kuntara Raja Niti dan Buku Ajar. Ranah: Jurnal Kajian Bahasa 3," Ranah J. Kaji. Bhs., vol. 3, no. 2, pp. 124-134, 2014, doi: https://doi.org/10.26499/rnh.v3i2.43.

[14] P. Bhattacharyya, Machine Translation. Boca Raton: Taylor \& Francis Group, 2015.

[15] D. Jurafsky and J. Marti, H, An Introduction to Natural Language Processing, Computational Linguistics, and Speech Recognition, vol. 3, no. 2. Prentice-Hall, Inc., 2008. 